\title{
TEMAS DE FILOSOFIA DO DIREITO
}

\author{
Alexandre Augusto de Castro Corrêa \\ Professor Catedrático aposentado de Direito Romano da \\ Faculdade de Direito da Universidade de São Paulo
}

\begin{abstract}
Resumo:
$\mathrm{O}$ autor aborda, dentre os vários temas, a conceituação universal do Direito, o jusnaturalismo neotomista, o jusnaturalismo liberal, comentários sobre a filosofia de Locke, Rousseau, Kelsen e outros.
\end{abstract}

\section{Abstract:}

The author approaches, amongst the some subjects, the universal conceptualization of the Right, the Neo-Thomism Natural Law, the liberal Natural Law, commentaries about the philosophy of Locke, Rousseau, Kelsen and others.

Unitermos: Ciência do Direito; Filosofia do Direito; conceituação universal do Direito.

A Ciência do Direito difere de sua filosofia. A primeira estuda os vários setores de normas coercitivas, regulando a vida social e postula a existência duma ordem jurídica admitida pelo consenso dos membros da comunidade. A Filosofia do Direito, por seu lado, procura justificar de modo racional e coerente os fundamentos da ordem jurídica. A Filosofia, em outras palavras, visa alcançar uma conceituação universal do Direito, válida para quaisquer tempos e lugares, como saber último que sempre pretende ser.

É este o primeiro e fundamental tema da Filosofia: a conceituação universal do Direito. Será possível obtê-la? A esse respeito divergiram sempre e continuam a divergir duas grandes correntes de pensamento, a do jusnaturalismo (neotomista ou liberal) e a positivista.

O jusnaturalismo neotomista, por exemplo, aceita a idéia romana do Direito como ars boni et aequi e admite um Direito Natural com valores absolutos, cujo fundamento último se encontra na inteligência e vontade do legislador supremo, Deus. O jusnaturalismo liberal de Locke e Rousseau, pelo contrário, fundamenta a 
ordem jurídica na razão natural do homem, dispensando, porém, a invocação da divindade como fiadora da primeira. Segundo Grócio, o princípio pacta sunt servanda continuaria válido mesmo que, por absurdo, Deus não existisse.

Já para o positivismo jurídico, Direito propriamente dito é só o conjunto de normas dotadas de força coercitiva a elas conferida pela autoridade do Estado. Não tendo por si mesmo tal força coercitiva e sendo meramente persuasivo, o chamado "Direito Natural" não passaria de parte da Moral. Para Kelsen só é jurídica a norma dotada de sanção estatal e que obedece às condições externas de sua validade. Segundo este representante do positivismo neokantiano, considerações a respeito da justiça ou injustiça da norma jurídica ou a respeito de sua conveniência ou oportunidade são de ordem "metajurídica"; vale dizer, irrelevantes tanto para a ciência quanto para a própria Filosofia do Direito.

Kelsen defende, pois, uma concepção puramente formal da regra de Direito; para ele a própria essência desta, consiste em sua força coercitiva e para subsistir não depende de qualquer conteúdo justo ou injusto. Dura lex sed lex: a lei, embora injusta, não deixa de ser lei. O jusnaturalismo não perde, é claro, a oportunidade de objetar que uma ordem jurídica sentida como injusta pela consciência social causa repulsa e freqüentemente origina sua substituição pacífica, ou mesmo violenta, por nova ordem considerada menos injusta.

E dessa verdade dá testemunho a história política dos povos em todos os tempos. Para o jusnaturalismo, pois, a visão positivista do Direito termina exatamente onde a Filosofia propriamente dita deve começar; na verdade, o positivismo ignora esta última, admitindo gratuitamente só a Ciência do Direito, divorciada, aliás, de qualquer cogitação a respeito da Justiça, enquanto nota constitutiva da noção de Direito, cujo valor normativo, pois, não dependeria só da sanção estatal. Semelhante crítica ao positivismo jurídico pode ser subscrita em nossos dias tanto por pensadores neotomistas quanto por um liberalismo protestante de tipo inglês ou americano.

Para Locke e os fundadores da república dos Estados Unidos da América a liberdade de locomoção, de pensamento, de crença e o direito de propriedade, por exemplo, são inerentes ao ser humano, pelo simples fato de ele existir como tal, e independentes do Estado, que não pode absolutamente suprimi-los. Os neo-escolásticos divergem dos liberais apenas enquanto fazem depender do legislador supremo o fundamento último do Direito Natural. É verdade, por outro lado, que dessa dependência resulta para os neoescolásticos uma visão jusnaturalista, que em vários pontos se opõe à dos liberais ou neoliberais. 
Voltando, porém, a Kelsen, a clamorosa objeção a respeito das leis injustas não parece atingir a concepção formalista, pois o filósofo vienense pode simplesmente responder: "a uma lei considerada injusta pode suceder outra considerada menos injusta, mas em ambas permanece constante e identico o elemento puramente formal do comando, emanado da autoridade estatal competente e revestido das condições formais de sua vigência"

Ora, a Filosofia do Direito parece dever tratar exatamente dos aspectos "metajurídicos" das normas, de modo que, reduzindo-se à consideração do Direito Positivo, Kelsen renuncia àquela. Sua "Teoria Pura" do Direito acaba confundindo-se com a mera Ciência do Direito e deixa em suspenso as questões propriamente filosóficas. Daí seu grande prestígio perante os juristas práticos. O mérito, porém, do jusnaturalismo neoescolástico ou liberal consiste em insistir com razão na relevância do conteúdo das normas jurídicas, enquanto tal conteúdo é encarado como nota essencial constitutiva da própria noção do Direito. Nesse sentido, dando conteúdo puramente econômico à ordem jurídica burguesa, o próprio marxismo apela para um ideal implícito de Justiça, utilizado como força moral propulsora da ação revolucionária.

O marxismo, pois, como os jusnaturalistas, rejeita a concepção puramente formal do Direito, que para o autor do Manifesto Comunista deverá, junto com o Estado burguês, desaparecer, substituídos ambos pela moral da fraternidade universal proletária.

Esforço interessante visando, ao que parece, conciliar antagonismos foi o de Stammler com sua idéia um tanto paradoxal de um "Direito Natural de conteúdo variável" Preceitos como bonum faciendum et malum vitandum, da concepção aristotélico-tomista, ou os juris praecepta do Direito Romano podem ser aceitos, para Stammler, como de valor absoluto. Levando-se porém em conta o modus vivendi próprio das sociedades humanas, a escravidão, a poligamia, a antropofagia e o sacrifício dos anciãos em ambientes de escassez ou penúria crônicas podem, entre outros exemplos, ser considerados toleráveis, se não aceitáveis, enquanto impostos por condições imperativas de sobrevivência.

As exigências absolutas da Moral supõem condições de "normalidade" que por diversas razões podem faltar e donde resulta a aplicação imperfeita dos imperativos éticos que continuam, entretanto, com valor absoluto num plano humano ideal. Não cabe aqui discutir a medida em que as visões de Stammler seriam conciliáveis com o jusnaturalismo tomista, por exemplo. Interessante é notar como a consciência da importância das considerações a respeito do conteúdo da norma jurídica vem na atualidade, preponderando sobre a apreciação puramente formalista da mesma. 
Em suma: jusnaturalistas de todos os matizes, marxistas e pensadores preocupados com o bem comum e a ordem social parecem unânimes em colocar no primeiro plano de suas cogitações o ideal de Justiça, como objeto próprio do Direito, revalorizando-se assim, indiretamente, o pensamento de Aristóteles e dos jurisconsultos romanos.

Outro tẹma de importância atual e conexo ao da Justiça parece ser o da Eqüidade. Os códigos envelhecem e não-acompanham o ritmo cada vez mais rápido das mudanças sociais; a legislação renovadora tarda. Nessas condições seria lícita a intervenção do Judiciário, criando situações novas, mesmo contra legem? No Brasil atual vemos a afirmação decidida em tal sentido por parte dos defensores da chamada "justiça alternativa". outorgando aos magistrados o poder de decidir por Eqüidade, a fim de sanarem desse modo graves conflitos sociais. Mas, em tal caso, onde vão parar a divisão de poderes do Estado e a certeza e garantia dos direitos, valores estes tãocaros a todos os liberais e neoliberais? Entre os romanos o problema não existiu, pois lá o pretor não tinha as mãos atadas pela doutrina de Montesquieu e pôde usar largamente da aequitas; e o mesmo, guardadas as devidas proporções, se diga a respeito da formação do Common Law, onde a Equity contribuiu amplamente para abrandar o rigor daquele. Mas, em regime de direito codificado reconhecendo a lei como única fonte do Direito, como retirar ao Poder Legislativo sua prerrogativa de declarar os direitos?

Inspirar-se-iam os defensores da "justiça alternativa" nas idéias de Geny, fundador, no começo deste século, da Escola chamada do "Direito livre" ou na Freie Rechtsfindung und freie Rechtswissenschaft de Ehrlich? Mas, em tal caso, é toda al ordem constitucional do país que entra em discussão, quando se quer "libertar os juízes de sua obediência fictícia à regra passando-se a confiar na consciência dos mesmos e em seu espirito de equiidade", como observa com exatidão Roubier.

Outro ponto litigioso, agitando intensamente o mundo jurídico, é o consistente em decidir se a paz e a ordem pública pairam acima da Justiça ou subordinam-se, pelo contrário, a esta, devendo-se fazer Justiça a todo transe mesmo à custa da guerra civil com todas as suas conseqüências (fïat justitica et pereat mundus!).

E que pensar da "sociedade permissiva" defendendo em nome de uma autonomia sem limites da vontade humana o aborto e a eutanásia, a legalização do uso de drogas, o "casamento" de homossexuais, a abolição da pena de morte mesmo nos homicídios mais atrozes, a descriminalização do furto, ctc.?

De qualquer forma se, como pensa o autor destas linhas, o Direito tiver por objeto a Justiça é certo que ele se encontrará sempre diante de alternativas trágicas: 
simbolizadas por Antígona, no mundo grego; pelos primeiros cristãos no mundo romano, pagando com a vida de seu testemunho em prol da nova fé; por Tomas Morus, inflexível diante de Henrique VIII; e pelos milhões de outros seres humanos imolando, em todos os tempos, suas existências na luta contra as tiranias, do poder, do dinheiro, das discriminações religiosas e raciais e de tantas outras.

São Paulo, março de 2001. 